\title{
Feasibility of minimally invasive approaches in patients with infected necrotizing pancreatitis
}

\author{
M. G. Besselink ${ }^{1}$, H. C. van Santvoort ${ }^{1}$, A. F. Schaapherder ${ }^{2}$, B. van Ramshorst ${ }^{3}$, H. van Goor $^{4}$ and $^{2}$ \\ H. G. Gooszen ${ }^{1}$ on behalf of the Dutch Acute Pancreatitis Study Group \\ Departments of Surgery, ${ }^{1}$ University Medical Centre Utrecht, Utrecht, ${ }^{2}$ Leiden University Medical Centre, Leiden, ${ }^{3}$ St Antonius Hospital, Nieuwegein \\ and ${ }^{4}$ Radboud University Nijmegen Medical Centre, Nijmegen, The Netherlands \\ Correspondence to: Professor H. G. Gooszen, Department of Surgery, University Medical Centre Utrecht, HP G04.228, PO Box 85500, 3508 GA Utrecht, \\ The Netherlands (e-mail: h.gooszen@umcutrecht.nl)
}

\begin{abstract}
Background: Minimally invasive procedures to treat infected necrotizing pancreatitis (INP) are gaining popularity. The proportion of patients suitable for this approach remains unknown.

Methods: Preoperative computed tomography (CT) scans were reviewed from 106 consecutive patients who had surgery for INP between 2000 and 2003 in 11 Dutch hospitals. Collections related to the pancreas were classified according to their distance from the left abdominal wall. Five radiologists judged 'accessibility' for drain placement and the likelihood that there was a fluid component that would drain ('drainability'). Agreement between radiologists was determined.

Results: CT scans of 80 (75 per cent) patients were available (59 men; age range 29-80 years). The median interval between hospital admission and preoperative CT scan was 20 days. In 55 (69 per cent) patients, the lateral border of the collection was less than $5 \mathrm{~cm}$ from the left abdominal wall. Placement of a drain was deemed feasible in 67 (84 (range 77-89) per cent) patients; mean(s.d.) kappa 0.428(0.096). In 45 (56 per cent) patients, a drain could be placed through the left retroperitoneum. In 43 (54 (range 49-82) per cent) patients, collections were judged to contain a drainable fluid component. Interobserver agreement on 'drainability' was poor, mean(s.d.) kappa 0.289(0.101).

Conclusion: Most peripancreatic collections in INP were considered accessible to a minimally invasive approach.
\end{abstract}

Presented to a meeting of the American Gastroenterological Association (Digestive Disease Week ${ }^{\circledR}$ ), Chicago, Illinois, USA, May 2005, and published in abstract form as Gastroenterology 2005; 128(Suppl 2):A171-A172.

Paper accepted 19 February 2007

Published online 21 March 2007 in Wiley InterScience (www.bjs.co.uk). DOI: 10.1002/bjs.5546

\section{Introduction}

Surgical intervention for suspected infected necrotizing pancreatitis (INP) is accompanied by a high morbidity and mortality ${ }^{1-4}$. In the past decade, surgery for INP has increasingly been delayed to allow for demarcation and encapsulation of the infected necrotic material ${ }^{3-5}$. This has been accompanied by a shift from open necrosectomy to minimally invasive procedures involving radiological and endoscopic approaches to drainage and surgery ${ }^{6-8}$.

In 1998, Freeny et al. described computed tomography (CT) - guided percutaneous catheter drainage of INP9 . Drainage of 'infected fluid under pressure' may improve the patient's clinical condition and postpone or even obviate the need for surgical intervention. If drainage does not lead to clinical improvement, the percutaneous drain can be used as a 'guidance drain' for minimally invasive (retroperitoneal) surgery. Several strategies for drain-guided surgery have been reported ${ }^{6-8,10,11}$. All the minimally invasive procedures (radiological, endoscopic or surgical) have a common first step, with the placement of a drain in the peripancreatic collection. The collections must therefore be accessible for drain placement if minimally invasive approaches are to be widely implemented. So far, results have been based on small series from expert centres open to criticisms of selection bias (only patients with amenable collections having been chosen, along with the least sick). Information on the distribution of peripancreatic collections in INP is also sparse. The 
location of these collections is important, as those extending close to the left flank are easily accessible for (retroperitoneal) drain placement, in contrast to those near the pancreatic head.

The present pilot study was undertaken for a Dutch nationwide trial comparing minimally invasive techniques for necrosectomy with laparotomy in patients thought to have INP. The aim was to evaluate the intraabdominal distribution, 'accessibility' and 'drainability' of peripancreatic collections in a large series of consecutive patients who had surgery for INP, to see what proportion of patients might be suitable for such a trial and what stratification might be necessary.

\section{Methods}

Between October 2000 and October 2003, 106 consecutive patients (older than 18 years) who had surgical intervention for suspected INP were identified by a database search in 11 Dutch hospitals, including all the university medical centres and three large teaching hospitals. Patients were included if a CT scan was available for review (Fig. 1). They were excluded if the indication for surgery had been acute bleeding or perforation of a visceral organ. The results of surgical treatment of these patients have been previously published $^{12}$.

Pre- and postoperative clinical and radiological records as well as preoperative CT scans were retrieved. The following variables were collected: patient age, sex, date of admission and date of preoperative CT scan. All preoperative CT scans were digitalized by high-resolution scanning (Diagnostic Pro ${ }^{\mathrm{TM}}$; Vidar Systems, Herndon, Virginia, USA). From each scan, two or three slices at different levels were selected, including the slice depicting the maximum diameter of the collection. These images were transferred to a computer slide presentation.

Scans were reviewed in consensus to classify peripancreatic collections by intra-abdominal location. The distance between the left lateral border of the collection and the left abdominal wall ('inner' abdominal wall, not the skin) was measured using the original metric scale on the CT scan. Interposition of intra-abdominal organs was taken into account. If possible, the shortest retroperitoneal route was chosen; if not, then the shortest route was measured from the lateral border of the collection to the abdominal wall. The collections were classified as follows: left (left lateral border of the collection $5 \mathrm{~cm}$ or less from the left abdominal wall), intermediate (left lateral border of the collection more than $5 \mathrm{~cm}$ from the left abdominal wall and $5 \mathrm{~cm}$ or less from the midline) or central (left lateral border of the collection less than $5 \mathrm{~cm}$ from the midline). When

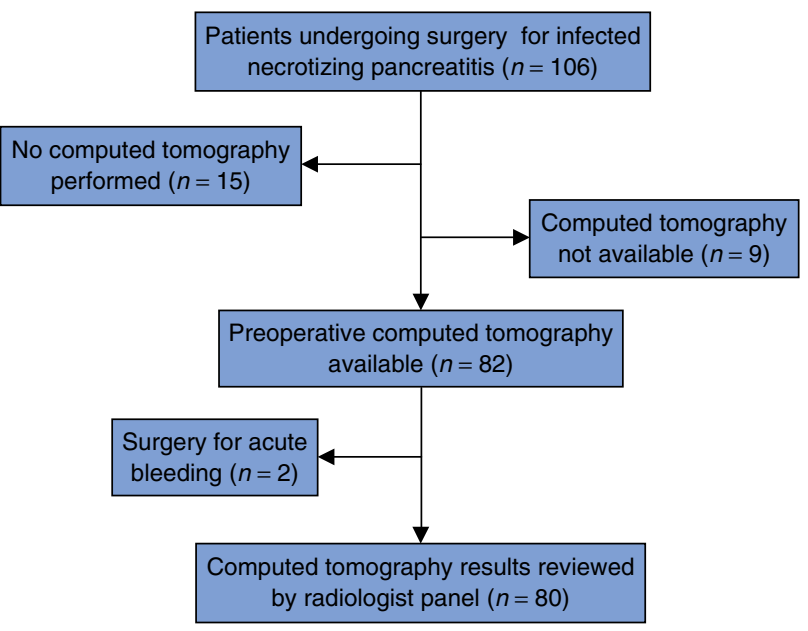

Fig. 1 Study flow chart

multiple collections were present, the most prominent was chosen.

Five experienced hepatopancreatobiliary radiologists from five Dutch tertiary referral centres independently reviewed the preoperative scans using the computer slide presentation and, if desired, the complete CT scan. They were unaware of the original radiological report but were given the dates of admission, CT scan and first surgical intervention. Each radiologist individually judged the accessibility of the peripancreatic collections for placement of a percutaneous or endoscopic transgastric drain in the collection. They were asked the following question, with the possible answers ranked in order on the basis that a left retroperitoneal drain is preferable for performing minimally invasive drain-guided surgery: 'Which route is most feasible and safe for the placement of a 14-French drain in the collection: (a) through the left retroperitoneal space, (b) through the right retroperitoneal space, (c) through the transperitoneal space, (d) through an endoscopic transgastric entrance or (e) no route possible?'. If drain placement was considered not possible, one of the following reasons had to be given: '(a) no safe access route present' or '(b) no physical collection present'.

Each radiologist then judged whether the peripancreatic collection was 'drainable'. A collection was defined as 'drainable' if it was expected to contain at least $50 \mathrm{ml}$ of aspirate immediately after first drain placement.

\section{Statistical analysis}

Statistical analysis was performed using SPSS $^{\circledR}$ software (SPSS $^{\circledR}$, Chicago, Illinois, USA). $P<0.050$ for a twotailed test was considered statistically significant. Unless 
indicated otherwise, results are given as means. The interobserver agreement was calculated using kappa statistics. The mean(s.d.) kappa coefficient was calculated for all ten possible radiologist pairs. A kappa level less than 0.000 represented no agreement, 0.000-0.200 slight, 0.210-0.400 fair, $0.410-0.600$ moderate, $0.610-0.800$ substantial and 0.810-1.000 almost perfect agreement ${ }^{13}$.

\section{Results}

Preoperative CT scans were available from 80 (75 per cent) of 106 patients. Fig. 1 shows the patient inclusion flow chart, and baseline characteristics are shown in Table 1. Of the peripancreatic collections, 55 (69 per cent) of 80 were classified as left, 19 (24 per cent) as intermediate and six ( 8 per cent) as central. Seven $(9$ per cent) patients had multiple collections.

Drain placement was considered feasible in 67 (84 (range 77-89) per cent) of 80 patients. The interobserver agreement for accessibility was moderate (kappa 0.428; s.d. 0.094). In 45 (67 per cent) of these 67, it was deemed feasible to place a retroperitoneal drain from the left flank (Table 2). Drain placement was more often feasible in left (50 of 55) than intermediate (12 of 19) and central

Table 1 Characteristics of 80 patients with necrotizing pancreatitis

$\begin{array}{ll}\text { Age (years) } & 57(29-80) \\ \text { Sex ratio }(\mathrm{M}: \mathrm{F})^{\star} & 59: 21(74: 26) \\ \text { Documented infected necrosis* }^{\star} & 63(79) \\ \text { Preoperative ICU admission* } & 38(48) \\ \text { Preoperative ICU stay (days) } & 8(1-105) \\ \text { Preoperative hospital stay (days) } & 20(1-179) \\ \text { Timing of computed tomography (days after } & 20(1-179) \\ \quad \text { admission) } & 6(2-10)\end{array}$

Values are median (range) unless otherwise indicated. ${ }^{*}$ Values are number of patients, with percentages in parentheses. Hospital and ICU stay includes time spent in referring hospitals. ICU, intensive care unit. collections (two of six) $(P<0.001)$. In the 13 patients in whom drainage was considered not possible, the reason was 'no safe access route' in 50 (range 25-77) per cent and 'no physical collection' in 50 (range 23-75) per cent. All radiologists agreed that it would not be possible to place a drain in only two $(2.5$ per cent $)$ of 80 patients. In one of these, no safe percutaneous or transgastric access route could be found, and in the other the scan showed pancreatic necrosis but no physical collection.

In 43 (54 (range 49-82) per cent) of 80 patients, the radiologists designated the collection as 'drainable'. The interobserver agreement for 'drainability' was fair (kappa 0.289; s.d. 0.101).

\section{Discussion}

The present pilot study for a trial comparing minimally invasive procedures with laparotomy in INP demonstrated that most (84 per cent) peripancreatic collections in INP are accessible from a minimally invasive approach and that more than two-thirds are within $5 \mathrm{~cm}$ of the left abdominal wall.

Success rates of percutaneous catheter drainage in INP (defined as obviating the need for surgery) vary from 30 to 100 per cent ${ }^{9,14-16}$. Several variations of minimally invasive 'drain-guided' surgery have been reported with mortality rates of 0 to 27 per cent $^{6-8,10}$ and it has been suggested that minimally invasive procedures are possible only in a subgroup of patients. The present results contradict this, with drainage deemed feasible in 84 per cent of patients.

The present study discriminated between 'accessibility' and 'drainability'. The interobserver agreement for 'accessibility' was moderate, probably representing different levels of experience with placement of percutaneous drains. 'Drainability' was arbitrarily defined as anticipated aspiration of more than $50 \mathrm{ml}$ at the time of first drain placement. Agreement on drainability of the peripancreatic collections among radiologists was poor. This

Table 2 Preferred route of drain placement based on appearance by computed tomography

\begin{tabular}{|c|c|c|c|c|c|c|}
\hline Radiologist & Not possible & $\begin{array}{l}\text { Left } \\
\text { retroperitoneum }\end{array}$ & Right retroperitoneum & $\begin{array}{c}\text { Anterior } \\
\text { transperitoneal }\end{array}$ & $\begin{array}{c}\text { Transgastric } \\
\text { endoscopic } \\
\text { procedure }\end{array}$ & Total \\
\hline 1 & $12(15)$ & $50(63)$ & $2(3)$ & $11(14)$ & $5(6)$ & $80(100)$ \\
\hline 2 & $9(11)$ & $57(71)$ & $0(0)$ & $9(11)$ & $5(6)$ & $80(100)$ \\
\hline 3 & $16(20)$ & $43(54)$ & $0(0)$ & $16(20)$ & $5(6)$ & $80(100)$ \\
\hline 4 & $11(14)$ & $38(48)$ & $3(4)$ & 27 (34) & $1(1)$ & $80(100)$ \\
\hline 5 & $18(23)$ & $35(44)$ & $1(1)$ & $19(24)$ & 7 (9) & $80(100)$ \\
\hline Mean & $13(16)$ & $45(56)$ & $1(1)$ & $16(20)$ & $5(6)$ & $80(100)$ \\
\hline
\end{tabular}

Values in parentheses are percentages. 
probably reflects the fact that CT cannot always discriminate between fluid and necrotic content in $\mathrm{INP}^{17,18}$. This finding should be kept in mind when considering the indication and expected outcome (drain production and clinical improvement) of percutaneous drainage.

In the present series, retroperitoneal drain placement from the left flank and hence minimally invasive 'drainguided' retroperitoneal surgery was deemed feasible in 56 per cent of unselected patients with INP. These findings are in line with the largest published case series, in which drain-guided retroperitoneal necrosectomy was achieved in 47 of 88 patients $^{7}$. Future studies will need to allow for the fact that not all collections are accessible from a retroperitoneal approach and that necrosectomy from a transperitoneal approach (laparotomy or laparoscopy) will remain useful.

The wider implementation of minimally invasive procedures for INP should be based on prospective, controlled studies undertaken by dedicated multidisciplinary teams ${ }^{1,4}$. To that end, the Dutch Acute Pancreatitis Study Group has recently started a prospective, randomized, multicentre trial to compare the minimally invasive approach with laparotomy in $\mathrm{INP}^{19}$.

\section{Acknowledgements}

The authors thank the radiologists who reviewed the CT scans: T. L. Bollen, M. S. van Leeuwen, J. S. Lameris, S. P. Strijk and E. J. van der Jagt. The authors also thank Dr P. Westers, Centre for Biostatistics, Utrecht University, for assistance with statistical analysis and F. E. Tymstra, Department of Radiology, University Medical Centre Utrecht, for the digitalization of CT scans. M. G. H. Besselink is an MD medical research trainee for the Netherlands Organization for Health Research and Development (ZonMw, grant no. 920-03-368).

\section{References}

1 UK Working Party on Acute Pancreatitis. UK guidelines for the management of acute pancreatitis. Gut 2005; 54(Suppl 3): iii1-iii9.

2 Nieuwenhuijs VB, Besselink MG, van Minnen LP, Gooszen HG. Surgical management of acute necrotizing pancreatitis: a 13-year experience and a systematic review. Scand 7 Gastroenterol Suppl 2003; 239: 111-116.

3 Uhl W, Warshaw A, Imrie C, Bassi C, McKay CJ, Lankisch PG et al. IAP guidelines for the surgical management of acute pancreatitis. Pancreatology 2002; 2: $565-573$.

4 Werner J, Feuerbach S, Uhl W, Buchler MW. Management of acute pancreatitis: from surgery to interventional intensive care. Gut 2005; 54: 426-436.
5 Mier J, Luque-de León E, Castillo A, Robledo F, Blanco R. Early versus late necrosectomy in severe necrotizing pancreatitis. Am 7 Surg 1997; 173: 71-75.

6 Carter CR, McKay CJ, Imrie CW. Percutaneous necrosectomy and sinus tract endoscopy in the management of infected pancreatic necrosis: an initial experience. Ann Surg 2000; 232: 175-180.

7 Connor S, Ghaneh P, Raraty M, Sutton R, Rosso E, Garvey CJ et al. Minimally invasive retroperitoneal pancreatic necrosectomy. Dig Surg 2003; 20: 270-277.

8 Horvath KD, Kao LS, Wherry KL, Pellegrini CA, Sinanan MN. A technique for laparoscopic-assisted percutaneous drainage of infected pancreatic necrosis and pancreatic abscess. Surg Endosc 2001; 15: 1221-1225.

9 Freeny PC, Hauptmann E, Althaus SJ, Traverso LW, Sinanan M. Percutaneous CT-guided catheter drainage of infected acute necrotizing pancreatitis: techniques and results. A7R Am f Roentgenol 1998; 170: 969-975.

10 Castellanos G, Serrano A, Piñero A, Bru M, Párraga M, Marín $\mathrm{P}$ et al. Retroperitoneoscopy in the management of drained infected pancreatic necrosis. Gastrointest Endosc 2001; 53: 514-515.

11 Gambiez LP, Denimal FA, Porte HL, Saudemont A, Chambon J-PM, Quandalle PA. Retroperitoneal approach and endoscopic management of peripancreatic necrosis collections. Arch Surg 1998; 133: 66-72.

12 Besselink MG, de Bruijn MT, Rutten JP, Boermeester MA, Hofker HS, Gooszen HG. Surgical intervention in patients with necrotizing pancreatitis. Br 7 Surg 2006; 93: 593-599.

13 Landis JR, Koch GG. The measurement of observer agreement for categorical data. Biometrics 1977; 33: 159-174.

14 Echenique AM, Sleeman D, Yrizarry J, Scagnelli T, Guerra JJ, Casillas VJ et al. Percutaneous catheter-directed debridement of infected pancreatic necrosis: results in 20 patients. 7 Vasc Interv Radiol 1998; 9: 565-571.

15 Gouzi JL, Bloom E, Julio C, Labbe F, Sans N, el Rassi Z et al. [Percutaneous drainage of infected pancreatic necrosis: an alternative to surgery.] Chirurgie 1999; 124: 31-37.

16 Mithofer K, Mueller PR, Warshaw AL. Interventional and surgical treatment of pancreatic abscess. World 7 Surg 1997; 21: $162-168$.

17 Morgan DE, Baron TH, Smith JK, Robbin ML, Kenney PJ. Pancreatic fluid collections prior to intervention: evaluation with MR imaging compared with CT and US. Radiology 1997; 203: 773-778.

18 Ward J, Chalmers AG, Guthrie AJ, Larvin M, Robinson PJ. T2-weighted and dynamic enhanced MRI in acute pancreatitis: comparison with contrast enhanced CT. Clin Radiol 1997; 52: 109-114.

19 Besselink MG, van Santvoort HC, Nieuwenhuijs VB, Boermeester MA, Bollen TL, Buskens E et al., Dutch Acute Pancreatitis Study Group. Minimally invasive 'step-up approach' versus maximal necrosectomy in patients with acute necrotizing pancreatitis (PANTER trial): design and rationale of a randomized controlled multicenter trial [ISRCTN38327949]. BMC Surg 2006; 6: 6. 


\section{Appendix}

\section{Dutch Acute Pancreatitis Study Group}

The following centres and study group members contributed patients (number of patients). University Hospital Groningen (15): H. S. Hofker, E. J. van der Jagt, R. J. Ploeg; University Hospital Maastricht (13): J. P. Rutten, C. De Jong; Academic Medical Centre, Amsterdam (9): D. J. Gouma, J. S. Lameris, M. A. Boermeester; St Antonius Hospital, Nieuwegein
(9): T. L. Bollen, B. van Ramshorst; Leiden University Medical Centre (8): A. F. M. Schaapherder; University Medical Centre Utrecht (7): M. G. H. Besselink, H. C. van Santvoort, M. S. van Leeuwen, E. Buskens, H. G. Gooszen; Vrije Universiteit Medical Centre, Amsterdam (6): M. A. Cuesta; UMC St Radboud, Nijmegen (4): S. P. Strijk, H. van Goor; Erasmus MC, Rotterdam (3): C. H. J. van Eijck; Medical Centre Rijnmond Zuid, Rotterdam (3): N. Wijffels, L. van Walraven, J. Lange; Leeuwarden Medical Centre (3): J. P. E. N. Pierie. 